\title{
RELIGIÃO, RELIGIOSIDADE E CONTEXTO DO TRABALHO
}

\author{
por Deis Siqueira*
}

NASH, Laura; MCLENNAN, Scotty. Igreja aos domingos, trabalho às segundas: o desafio da fusão de valores cristãos com a vida dos negócios. Prefácio de Ken Blanchar. Trad. Carlos Henrique Trieschmann. Rio de Janeiro: Qualitymark, 2004. 337 p.

Como a religiosidade está sendo ressignificada e re-apropriada na atualidade?

O pressuposto principal, no qual se ancora esta pergunta, é o de que a religiosidade fornece, sobretudo, atribuição de sentido, ou nomização, como diria Berger (referenciado no conceito de anomia de Durkheim).

Afora outras dimensões da religião (e da religiosidade), vale destacar que ela também pode funcionar como mecanismo de controle social/exploração/expropriação, podendo, portanto, ser instrumentalizada pelas elites ou grupos dirigentes de uma sociedade, em seu momento histórico.

Como crenças, valores, conceitos, práticas religiosas estão sendo ressignificados tanto em termos de atribuição de sentido, quanto em termos de controle/instrumentalização, na atualidade?

A religiosidade foi considerada até recentemente, sobretudo, como uma expressão da vida e da moral privadas e, portanto, parte da dimensão da subjetividade (escolha pessoal/fé). Tanto assim que

* Pesquisadora do CNPq e pesquisadora Associada do Departamento de Sociologia da UnB. 
Berger, em sua obra $O$ dossel sagrado, já anunciara, há várias décadas, o processo de psicologização da religião.

E a religião ou religiosidade passa a ser, crescentemente, instrumentalizada por empresas, batizada, nos últimos anos, como espiritualidade no contexto do trabalho.

Nash (pesquisadora sênior da Harvard Business Scholl) e McLennan (advogado e reitor de vida religiosa na Universidade de Stanford), ancorados em consistente pesquisa empírica junto a empresas e ao clero, explicitam o impasse gerado pelo vácuo de referência baseada na fé cristã e uma rejeição mútua entre pessoas de negócios e pessoas de religião.

Ambos os grupos teriam se enfraquecido, devido à entropia $\mathrm{e}$ esquizofrenia religiosa, guerra territorial, demonização, estereótipos mútuos. Daí o título da obra referir-se à desconexão entre o culto dominical e o cotidiano (as segundas-feiras).

Os autores indicam a incapacidade da Igreja para lidar com o mundo do trabalho e a simultânea crescente busca por orientações religiosas alternativas, as quais girariam em torno da espiritualidade. Porque essas preencheriam a lacuna, permitindo melhores negociações entre economia e religiosidade, oferecendo variadas opções de acesso (gurus, técnicas, programas gerenciais de conforto). Segundo os autores, esse processo não estaria transformando apenas os negócios, mas a própria religião norte-americana.

De fato, o fenômeno é mais abrangente. Nessa direção está sendo desenvolvida, desde 1994, uma investigação com o apoio do CNPq, no Departamento de Sociologia ${ }^{1}$ em torno da Sociologia das Adesões: práticas místicas e esotéricas em Brasília. Uma de suas etapas foi uma pesquisa realizada em dezesseis universidades de dez países ocidentais, incluindo-se os EUA, a qual favorece generalizações sobre a investigação regional.

Identifica-se, no Ocidente (ainda que também em países como o Japão, depois da segunda Guerra Mundial), um rápido crescimento 
da busca por novas formas de religiosidade; por um novo estilo de vida, identificável, sobretudo, pelo consumo de práticas nãoconvencionais ou alternativas em particular pelos estratos privilegiados da sociedade (acupuntura, homeopatia, florais, vários tipos de massagem, vegetarianismo, viagem astral, tarot, runas, literatura de auto-ajuda).

Compõem a nebulosa esotérica, ou campo religioso ampliado, religião difusa, religiosidade flexível flutuante, espaço religioso ou novas forma do sagrado, nova sensibilidade místico-esotérica ou esotérico-holista da New Age, nebulosa polivante da New Age, novas formas de religião, crédulos difusos, nebulosa heterodoxa, religiões seculares, religiosidade inorgânica, dentre muitas outras denominações que se encontram na literatura existente a respeito.

Há vários movimentos correlatos e bastante instigantes entre a busca por novas formas de religiosidade (âncora do crescimento das Novas Religiosidades e da busca por práticas não convencionais ou alternativas) e deslocamentos que vêm ocorrendo em outras dimensões da construção do cotidiano, destacando-se a espiritualidade no contexto do trabalho.

De fato, grandes organizações, tais como Xerox, Mary Kay Cosmetics, Southwest Airlines, Banco Mundial, têm sido identificadas como bastante "espiritualizadas". Isso porque elas estariam proporcionado a seus funcionários treinamentos que trazem para o ambiente de trabalho uma nova perspectiva de auto-realização, via espiritualidade no contexto do trabalho.

Também outras empresas, tais como a Ford Motor Co, Boeing, Lótus Development, AT\&T e Du Pont, têm trabalhado junto a seus gerentes e empregados uma nova visão de busca de paz interior, verdade, não-violência e amor, o que, segundo alguns autores, seriam pontos essenciais da espiritualidade no trabalho.

É dentro de uma perspectiva mais ampla de compreensão de religiosidade (em relação ao conceito de religião) e de psicologização da religião que, talvez, se possa entender porque espiritualidade parece 
estar sendo considerada, fundamentalmente, como a procura por valores, por conexões, por vivências, que transcendam a materialidade. Uma postura de vida que buscaria sentido, significado para o estar no mundo (família, trabalho) e equilíbrio entre as diversas esferas da vida (racional, afetiva, social).

Essa espiritualidade tende a ser enfatizada em uma dimensão mais ligada a significados típicos das Novas Religiosidades (autoaperfeiçoamento, auto-desenvolvimento, auto-crescimento), a valores de uma postura humanista diante do mundo (amor, respeito ao próximo, fraternidade, ecologia), do que à religião institucionalizada.

Os discursos em torno da espiritualidade no contexto do trabalho tratam de explicitar que não se trata de religião, similar aos discursos dos buscadores de novas formas de religiosidade (anticlericais, anti-dogmáticas, anti-hierárquicas) e às falas dos terapeutas não-convencionais (que tendem a enfatizar o caráter científico passível de comprovação - de seus conhecimentos e práticas, negando, em princípio, suas conexões com as Novas Religiosidades).

Pode-se pensar em termos de re-composição de religiosidade \& psicologia \& terapia, crescentemente identificada como espiritualidade. Conceito ressignificado: objetiva desassociar suas crenças, práticas, princípios, da Religião (Instituição).

No mundo organizacional, em particular, essa expansão do movimento de espiritualidade no ambiente de trabalho parece se inserir em uma nova perspectiva paradigmática que busca, atrelada à produtividade e a novas oportunidades de negócios, uma maior criatividade, sinergia, conectividade, satisfação pessoal dos trabalhadores.

$\mathrm{Na}$ literatura específica (sobretudo aquela relativa à Administração), fala-se em valores individuais de crescimento e maturidade, em maior identificação com a atividade. Enfatizam-se a intuição, a criatividade, a cooperação, o trabalho em equipes, o equilíbrio, a totalidade, a conectividade e não mais o status na organização, aumento da renda, poder de controle. Indica-se uma 
nova perspectiva paradigmática, onde as empresas estariam mais suscetíveis aos valores individuais de seus empregados, integrando outros valores, tais como sustentabilidade, igualdade social, transcendência do individualismo, consciência mais coletiva, capital humano.

Assumir um sentido compartilhado e claro poderia tornar a organização uma comunidade em que o trabalho permitiria satisfação e sentido profundos. Assim, o trabalho passaria a ser não apenas uma atividade, porque poderia assumir um sentido vocacional que transcenderia interesses e conflitos pessoais, e poderia assumir uma ideologia de ação transcendental ou espiritualizada. Se o trabalho for orientado para além do senso individual, poderia ser visto como vocação, experimentando significado e satisfação. Sob essa perspectiva, tanto o trabalho quanto a organização poderiam se tornar fontes de desenvolvimento interpessoal e espiritual.

Essas mudanças refletiriam uma busca por outros significados na vida pessoal e profissional, onde a espiritualidade se tornaria fundamental para o desenvolvimento dos trabalhadores. Essa espiritualidade no trabalho poderia ser compreendida também a partir da busca inerente e universal por um significado e um propósito maior de vida.

Nesse sentido, estão sendo qualificados ou re-qualificados supostos valores como sendo característicos do feminino, tais como intuição, sensibilidade, tolerância, compreensão, os quais se transmutam, ou se revestem, sobretudo, na Administração, em parceria, cooperação, rede, ancorados em significados da espiritualidade (ou religiosidade/humanidade) no contexto de trabalho (fraternidade, solidariedade, cooperação, conectividade).

A literatura sobre espiritualidade no contexto do trabalho parece se ancorar em três eixos principais: a) ambiente de trabalho pensado como boa conduta, bem-estar, amor, integridade, verdade, saúde, felicidade, paz interior; b) trabalho com significado e sentido, em lugar de relações profissionais; e c) o indivíduo como referência, interconectividade, comunidade, parcerias, redes. 
Bem, parto do pressuposto que se trata de uma instrumentalização da religião/religiosidade, com o objetivo primeiro de aumentar a produtividade dos trabalhadores e, portanto, os lucros para a empresa.

Mas, de alguma maneira o movimento tende a se alinhar com a crescente e já referida busca por novas formas de religiosidade/ espiritualidade na sociedade envolvente, para além do contexto do trabalho. Segundo a bibliografia disponível, as representações dos trabalhadores (subjetividade) tendem a se aglutinar em torno de valores humanitários gerais (amor, fraternidade); do movimento de psicologização da religião (bem-estar, tranquuilidade, equilíbrio, satisfação).

E os autores da obra Igreja aos domingos, trabalho às segundas são claros quanto a seu desejo de recuperação de espaço por parte da Igreja. Ou seja, tentam indicar a possibilidade de um engajamento entre ela e os negócios. O lugar da fé seria importante para os negócios, porque ela reafirmaria uma estrutura maior pela qual se pode medir o progresso em direção a Deus. No sentido desse resgate, o livro indica sugestões para as pessoas de religião e para as pessoas do mundo dos negócios.

$\mathrm{Na}$ verdade, não obstante a pesquisa empírica ter sido consistente (Harvard é Harvard), o texto pretende oferecer uma diretriz para se testar atitudes e realizações a partir da experiência do empresário. Para que uma vida de fé no contexto dos negócios se reconstrua, os autores indicam vários níveis de engajamento religioso. Eles afirmam a nova espiritualidade como uma contribuição legítima, mas pontualizam, durante toda a obra, seus limites. Afinal, a Igreja deve, segundo eles, acessar seu dinamismo.

Mas lembrando William James, citado no livro, certos tipos de personalidade são atraídos por experiências diferenciadas. E a busca por novas formas de religiosidade (anti-clerical, anti-hierárquica, antidogmática) é um fenômeno social irreversível no Ocidente contemporâneo. 
Portanto, a leitura da obra é indicada. Por vários motivos.

A busca pelo misterioso, pelo sagrado, pelo numinoso, pelo divino, ou como se denomine essa busca por religiosidade (anterior à constituição das religiões) ou por espiritualidade (no sentido clássico de enfrentamento/transcendência da materialidade) é constituinte da condição humana. A obra se ancora em uma pesquisa consistente e interessante, recentemente realizada no país-império da atualidade, ou seja, os Estados Unidos da América (do Norte).

Ainda, exercitar o privilégio de se fazer Sociologia Crítica. De se atualizar a vitalidade, em particular, da Sociologia Crítica da Administração, ou da ciência do business, produzida em Harvard.

Não é demais lembrar que no prólogo do livro, Ken Blanchard (Center for Faith Walk Leadership, autor de vários livros sobre valores e negócios, em vários deles buscando criar diálogo negócios-igreja), oferece pérolas, tais como:

Líderes de negócios precisam de ajuda e precisam do tipo de ajuda que podem obter da mensagem de liderança de Jesus (...) Igrejas precisam de ajuda para enfrentar os desafios da mudança e da feroz competição em seus domínios. Líderes de negócios sabem coisas que podem ajudar líderes religiosos. Sabem a respeito de marketing, conhecem finanças, sabem de toda sorte de coisas que são necessárias para gerenciar um negócio de forma eficaz - e uma igreja é um negócio baseado na fé (...) Cite qualquer coisa que promova a liderança eficaz; Jesus o fez, incluindo encorajar seus seguidores a pensarem além de suas necessidades e metas pessoais: a alimentar os famintos, acolher os desabrigados e visitar os enfermos e aprisionados (...) Valores cristãos e a vida dos negócios são sinérgicos.

A Sociologia pode vislumbrar a importância ou a centralidade estratégica da religião/religiosidade/espiritualidade para se compreender os atuais mecanismos de dominação, exploração, subordinação.

Parece que fazer uma Sociologia Crítica de outras áreas de conhecimento e ancorar nossa reflexão sobre investigações e conclusões realizadas por investigadores de Harvard e de Stanford 
como objeto é um privilégio para se compreender o capitalismo contemporâneo. Porque se trata de um tempo em que a contradição capital-trabalho crescentemente se maquia, diluindo seu lugar de contradição principal para se compreender as relações de dominação hegemônicas.

Aqui se tem uma produção pontual, para atualizar sobre como ainda se vive no capitalismo e como ele instrumentaliza, na atualidade, valores universais da condição humana. Contando, para tanto, com produções científicas, as quais seguem, sob novas formas, contribuindo para diluir as contradições da relação capital-trabalho. Produções de Harvard... para o mundo. Pelo menos ocidental.

\section{Nota}

1 Coordenada por Deis Siqueira, tendo dela participado os professores Lourdes Bandeira, Salete Kern Machado e Eurico Cursino, como consultor (com apoio da FAP-DF), além de inúmeros alunos de graduação e de pós-graduação dos Departamentos de Sociologia e de Antropologia, dentre outros. Os resultados dessa investigação podem ser localizados em várias publicações, destacando-se os livros: SIQUEIRA, D. As novas religiosidades no Ocidente: Brasília, cidade mística. Brasília: Edunb, 2003; SIQUEIRA, D.; LIMA, R. B. de. Sociologia das Adesões: novas religiosidades e a busca místico-esotérica na capital do Brasil. Rio de Janeiro: Garamond; Goiânia: Vieira, 2003. 